\title{
LAS REFORMAS CONSTITUCIONALES Y LA CONSOLIDACIÓN DEMOCRÁTICA
}

\author{
Alberto Ricardo Dalla Via*
}

RESUMEN: La Constitución Nacional Argentina y su contenido axiológico son el resultado de un devenir histórico que ha logrado plasmar en ella el desarrollo cultural y político del pueblo argentino. Ello permite al autor afirmar que los principios constitucionales no deben independizarse de la realidad social circundante, que abarca la experiencia bistórica, las preferencias sociales y el sentimiento colectivo.

Palabras Clave: Historia constitucional - Poder constituyente derivado - reforma constitucional - interpretación constitucional.

\section{The Constitutional REFORMS AND THE DEMOCRATIC CONSOLIDATION}

ABSTRACT: The National Constitution of Argentina and its axiological contents are the result of bistorical happenings that have captured the cultural and political development of the Argentinean people. This allows the author to state that the constitutional principles should not be independent of the surrounding social reality that comprises the historical experience, the social preferences and the collective sentiment.

KEY wORDS: Constitutional History - Derived Constituent Power - Constitutional Reform - Constitutional Interpretation.

SUMARIO: I. La Constitución Histórica. II. La influencia de Juan Bautista Alberdi. III. La Reforma de 1860. IV. Las reformas constitucionales posteriores. V. La reforma constitucional de 1994. VI. El poder constituyente derivado o reformador.

Abogado y Doctor en Derecho por la U. de Buenos Aires. Profesor Titular de Derecho Constitucional en la U. de Buenos Aires (Argentina) y en la U. de Belgrano (Argentina). Vicepresidente de la Asociación Argentina de Derecho Constitucional. Correo electrónico: Alberto.Dalla-Via@c6.pjn.gov.ar

Fecha de recepción: 25 de septiembre de 2006.

Fecha de aprobación: 17 de noviembre de 2006. 


\section{LA CONSTitución HistóRica}

La Constitución sancionada por la Convención Constituyente en Santa Fe el 1 de mayo de 1853 , no fue un acto espontáneo, sino la consecuencia de un devenir histórico en el que se fueron produciendo sucesivos documentos y pactos preexistentes muchos de los cuales se reflejan directamente en el articulado de nuestra Constitución Nacional $\mathrm{y}$ en su contenido axiológico.

Las luchas civiles entre unitarios y federales demoraron la organización institucional del país a lo que solo se llegó cuando se sintetizaron ambas posiciones y después de regar con mucha sangre el suelo argentino. La historia de nuestro país se ha caracterizado por la presencia casi permanente de líneas o facciones políticas en pugna, conforme lo ha descrito Félix LUNA al señalar los "conflictos y armonías de la historia argentina".

De ese modo, y desde la colonia hemos tenido divisiones y enfrentamientos entre españoles y criollos, "linieristas" y "alzaguistas" durante las invasiones inglesas; "morenistas" y "saavedristas" una vez producida la Revolución de Mayo; "unitarios" y "federales" durante la organización nacional; y más tarde entre "crudos" y "cocidos"; "chupandinos" y "lomos negros", para graficar las luchas entre autonomistas y nacionalistas; más tarde serán "radicales" y "conservadores"; "peronistas" y "antiperonistas"; "militaristas" y "antimilitaristas", etcétera.

Las antinomias se presentaron muchas veces como líneas paralelas que fueron recorriendo nuestra historia institucional, de manera que en algunos tramos o circunstancias dichas líneas enfrentadas lograron juntarse o sintetizarse a través de acuerdos que en no pocos casos fueron transitorios para después volver a confrontar. Hay quienes explican estas antinomias señalando que, en general, para los argentinos ha sido más importante "la parte" que "el todo", favoreciéndose de ese modo las actitudes sectarias.

El ideario de síntesis y de unión que produjo intelectualmente la llamada Generación del '37 a partir de la pluma de Esteban ECHEVERría se fue plasmando, a través de sucesivos proyectos en nuestro documento constitucional que fue apto, no solamente para organizar la "nueva y gloriosa nación" sino también para poner en marcha un proyecto de crecimiento y desarrollo - por intermedio de los hombres de la generación del ' 80 - que partía del ideario constitucional y que colocó a la Argentina entre las principales naciones del mundo.

Creemos en el valor de la Constitución como prenda de unión nacional, producto no solo de la necesidad de llevar a la letra los valores que anhelamos, sino también la experiencia de nuestra historia. En ella está

LUNA, Félix: "Conflictos y armonías en la bistoria argentina", Planeta. 
la síntesis de nuestra cultura y la forja de nuestra nacionalidad, con mucha sangre derramada y mucha tinta sobre hojas de pergamino. El camino de la Constitución fue muy largo y muchos nombres se inscriben en ella.

En los tiempos difíciles es bueno recrear el debate de las ideas fundacionales y recordar que fueron muchos los visionarios que, apuntalados sobre la solidez de la cultura y sobre nobles sentimientos de patriotismo imaginaron el país posible, fundado en la libertad y en la letra de la Constitución escrita.

La Convención general Constituyente de 1853, al igual que las convenciones constituyentes posteriores, tuvo en su seno una comisión redactora, que en el caso se llamó Comisión de Negocios Constitucionales y estuvo integrada por Pedro Díaz Colodrero, Martín ZAPATA, Juan Del Campillo, Manuel Leiva, Pedro Ferre, Juan María Gutiérrez y José Benjamín GorostiagA. La Comisión elevó el proyecto el 18 de abril de 1853 , precedido de un informe.

Las condiciones en medio de las cuales se reunía el Congreso general Constituyente eran de suma gravedad, aunque ZuVIRÍA expresó con inolvidables palabras el significado de la reunión: consolidar el programa de unión, orden, libertad, olvido y confraternidad "inscriptos en su bandera como el único lema digno de la época y de los pueblos argentinos".

Desde el comienzo mismo de las sesiones volvería a presentarse una vieja cuestión: la de la oportunidad del dictado de la Constitución en las circunstancias en que se encontraba el país. Se reanudaba así, el antiguo problema que se venía trajinando desde los inicios del Pacto federal, desde su propio contexto y que obligaba a considerar si se había llegado, en efecto, al momento oportuno de dictar la Constitución o sea si nos encontrábamos en estado de paz y tranquilidad para ello ${ }^{2}$.

El diputado ZENTENO rompió el fuego; en la sesión del 10 de abril expresó que si bien había que dar una Constitución y era deber de los representantes cumplir tal cometido, atento las circunstancias por las que atravesaba el país se preguntaba si era el momento de dictarla. De tal manera en el Congreso se expresaba que los pueblos deseaban una Constitución, que la pedían a sus representantes, pero que se habían presentado diferentes problemas que podían determinar la inoportunidad de su dictado o su propia frustración ${ }^{3}$ y así toda Constitución dictada en tales circunstancias serviría para forjar el despotismo o provocar la anarquía,

2 Galetti, Alfredo: Historia Constitucional Argentina, Librería Editora Platense, Tomo 2, p. 512 .

3 Ravignani, Emilio: Asambleas Constituyentes Argentinas, publicada por el Instituto de Investigaciones Hiscóricas de la facultad de Filosofía y Letras de la Universidad de Buenos Aires, v. IV, p. 471. 
haría retroceder a los pueblos más allá de su punto de partida; sería necesaria una seria preparación previa en los pueblos y también la suficiente serenidad espiritual para no recaer en errores que podrían ser fatales al desarrollo del país. ZaVALía también se inclinó en un primer momento por esa opinión.

A ello GUTIÉRREZ le replicaría con célebres palabras "La Constitución no es una teoría; como se ha dicho; nada más práctico que ella; es el Pueblo, es la Nación Argentina becha ley y encerrada en este Código que encierra la tiranía de la ley, esa tiranía santa, única a que yo y todos los argentinos nos rendiremos gustosos. Los pueblos nos la piden con exigencia porque ven en ella su salvación; y es por otra parte la oportunidad más aparente para dársela; debemos hacerlo sin pérdida de tiempo y pretender su aplazamiento es una acción que no me atrevo a calificar" ${ }^{\prime \prime}$.

\section{La influencia de Juan Bautista Alberdi}

Poco tiempo después de la batalla de Caseros, Juan Bautista AlBerDI y su fraternal amigo Juan María GuTiérReZ viajaban desde el Perú a Chile cuando recibieron en Cobija la noticia de ese acontecimiento. El primero, de inmediato, empezó a escribir la obra que tituló "Bases y puntos de partida para la organización política de la República Argentina". Es interesante adentrarse en el propio relato de los autores: "Veníamos de Lima para Chile en los primeros días de 1852, cuando oímos en Cobija la primera noticia de la caída de Rosas. No queríamos creerla por lo contradictorio del tiempo con la distancia de Buenos Aires a Bolivia. Pero en Valparaíso, al fondear el vapor "Nueva Granada" que nos tenía a su bordo, y antes que la policía marítima visitara el buque, un argentino venido a recibirnos, nos arrojó envuelta desde su bote, una gran hoja de papel, mojado todavía, que contenía el parte de la batalla de Monte Caseros salido al instante de la prensa. Llegar a Valparaíso nos pareció llegar a la patria, lo cual solo resultó cierto para Gutiérrez: una sonámbula me babía dicho en 1850, que yo no entraría en mi país después de caído Rosas... Descendidos a mi quinta de la calle de las Delicias, en Valparaíso, Gutiérrez se puso a acomodar su equipaje para ir al Primer Congreso general Constituyente, como diputado obligado de la Nación libertada; y yo me puse a escribir las "Bases" de la Constitución, que mi amigo debía hacer sancionar por sus consejos persuadidos y persuasivos"s.

Una vez terminado el libro, su autor remitió sendos ejemplares del mismo a varias personas representativas de la época. En carta dirigida a Mitre, acompañando esa publicación, decía AlBERDI “...Las 'Bases' no son

RAVIGNANI: $o p$. cit., Vol IV, p. 480.

ALBERDI, Juan Bautista: "Juan María Gutiérrez. Biografías y autobiografías", en Obras Selectas de Alberdi, Ed. La Facultad, 1920, T. IV, p. 392. 
mías, porque ni el escritor ni el diputado hacen bases; las bace Dios, residen en los hechos normales, en las leyes naturales de la existencia y el desarrollo de las sociedades; y yo no be becho sino tomarlas por el estudio de la fuente. Lea despacio mi libro; nadie es más capaz de comprenderme y de completar y suplir lo que me falta, que usted. Es la obra de un bombre de bien, escrita sin ambición, ni espiritu de partido, ni segunda mira; se compone de ideas que ya usted me conocía $y$ de algunos aprecios nuevos que me ha sugerido el estudio estimulado por el interés de la patria entrada en el camino de sus grandes destinos...".

La publicación de las "Bases" tuvo el mayor éxito. El Presidente Justo José DE URQUIZA dispuso con fecha 14 de mayo de 1855 la edición de los trabajos de ALBERDI con fondos oficiales. Una medida similar dispuso el Presidente Julio Argentino RocA al dictar el decreto del 12 de noviembre de 1880. Con ese motivo, Bartolomé Mitre escribió una serie de artículos críticos sobre la obra de ALBERDI, argumentos que más tarde fueron seguidos por otros escritores como Paul GROUSSAC y Ernesto QUESADA.

Los críticos elaboraron como conclusión que, como los trabajos de ALBERDI no eran originales, los constituyentes recurrieron, en forma directa, a las fuentes de los mismos "...El proyecto de este (ALBERDI) fue solo un elemento concomitante de juicio -afirmó QUESADA-, porque se prefirió dar el primer lugar al original de ROSSI, más detenido y con menos desviaciones; de modo que, contra lo que comúnmente se cree -sin remitir a la prueba los quilates de las buenas intenciones- la influencia de ALBERDI en la Constitución de 1853 fue completamente secundaria..." “...La obra de Rossi sobre la Constitución de Suiza, los comentarios de STORY, traducidos al francés, y otras obras, fueron el arsenal constitucional de que se servían GOROSTIAGA y GUTIÉRREZ, porque juzgaban que ALBERDI era solo quien había popularizado las doctrinas de ROSSI..."7.

A esos argumentos críticos, corresponde replicar con otros de mucha fuerza y gran valía que realzan la importancia de la obra de ALBERDI y su real influencia en la labor constituyente de 1853.

ALBERDI, como Sarmiento, contempló el panorama nacional, auscultó sus necesidades, estudió sus problemas y, con visión genial de estadista, preparó un plan general y dijo: aquí está la solución de los males que nos aquejan. El proyecto de Constitución es el medio de realización de las doctrinas expuestas en las "Bases". Alberd no se preocupó de ser original; lo que interesaba en el momento era saber en qué forma desaparecerían nuestros desiertos; se trataba de conocer cómo progresaría la pa-

Ravignani, Emilio: Asambleas Constituyentes Argentinas, op. cit., Tomo VI, p. 778.

QUESADA, Ernesto: carta enviada al Dr. Juan A. González Calderón publicada en la obra de este, Derecho Constitucional Argentino, Ed. J. Lajounae y Cia., 1923. T. II, p. XXV. 
tria. Consultó libros argentinos y extranjeros, revisó constituciones y al conjunto de los datos extraídos de la teoría y de la práctica, les imprimió su sello personal al combinarlos y reunirlos para sacar conclusiones precisas de los mismos 8 .

En definitiva, podemos coincidir con que más allá de esa polémica o de las críticas que puedan formularles surge clara la influencia de las "Bases" y del "Proyecto" de Juan Bautista AlBerdi en los debates y en las actas de la Convención de 1853. Esa circunstancia no se ve disminuida por el hecho de que los convencionales conocieran también otras fuentes.

El Congreso General Constituyente siguió con muy pocas variantes el plan esbozado en el Proyecto. Muchos de los artículos conservan, inclusive, su redacción original. Por otra parte, como ya señalamos, ALBERDI no pretendió ser un tratadista original sino que las "bases" eran un llamado, una bandera que formaba parte de un programa de legislación y de acción.

La publicación del libro alcanzó gran repercusión en el país mientras sesionaba la Convención en Santa Fe, así se ha dicho que fue un verdadero best seller para su tiempo, con tres ediciones en un año. Por su parte, el viejo amigo y compañero de luchas de ALBERDI, Juan María GuTIÉRREZ, ocupó una banca de convencional en la Asamblea que dictó la Constitución. Su calidad de miembro de la comisión redactora del respectivo proyecto, y sus eximias condiciones personales, contribuyeron a que fuera una de las más destacadas figuras de la Convención.

De las actas de la Convención se desprende que AlBERDI gozaba de gran consideración y respeto en la Asamblea, el párrafo de la correspondiente Comisión de Negocios Constitucionales, donde se dice "Es la obra del pensamiento actual argentino, manifestado por sus publicistas", es bien sugerente y evidente. Tampoco puede afirmarse seriamente que la Convención de Buenos Aires de 1860 haya alterado sustancialmente la Constitución de 1853.

La polémica planteada en cuanto a la mayor o menor influencia que Alberd tuvo en definitiva en el texto final de la Constitución no atenúa su prestigio. Su talento ha sido reconocido por todos, incluyendo a SARMIENTO y a MITRE, sus más ardientes adversarios han admitido que el publicista orientó el célebre Congreso de Santa Fe en la memorable misión de darnos la Constitución Nacional, cimiento de la organización del Estado y factor de progreso y fuente de convivencia pacífica y digna de los habitantes del país?.

8 QueSADA, Ernesto: La figura bistórica de Alberdi, Imprenta Scherone, 2da. Edición, 1919 p. 21.

9. Díaz Arana (h) Juan José: Influencia de Alberdi en la Constitución Nacional. Juicio ante una controversia, Librería Jurídica Valerio Abeledo - Editor, Buenos Aires, 1947. 
Los aportes de Benjamín Gorostiaga, Mariano Fragueiro y de Pedro DE ANGELIS como influencias que nutrieron el texto de la Constitución Histórica de ningún modo empañan la notable influencia que tuviera Juan Bautista AlBerd desde las Bases y su Proyecto de Constitución para las provincias Unidas, así como desde El Sistema Económico y Rentístico de la Confederación Argentina según su Constitución de 1853, que significó la primera obra de interpretación de la Constitución Histórica.

\section{LA REFORMA DE 1860}

Algunos debates constituyentes han tenido gran importancia en la interpretación ordinaria de la Constitución, especialmente por la calidad de las personalidades que allí intervinieron y el grado de versación en Derecho público de los mismos.

Después de la batalla de Cepeda y del Pacto de San José de Flores del 11 de noviembre de 1859, el Estado de Buenos Aires se reservó el derecho de aceptar lisa y llanamente la Constitución de 1853 o de proponer reformas a la misma. Entre los 75 convencionales elegidos por el pueblo de la Ciudad unos, y por las distintas secciones de la campaña otros, se encontraban, sin distinción entre unitarios y federales, ni entre porteños o provincianos, los abogados, los médicos, los escritores, los militares y los estancieros de más prestigio y renombre.

La jerarquía de sus componentes dio a la Asamblea bonaerense una importancia superior a la de su poder. De ahí que, cuando la mayoría derrota a los 17 convencionales que reclaman la incorporación inmediata de Buenos Aires, y decide examinar la Constitución para proyectar la reforma, se realiza una tarea constitucional de alto nivel.

SARMIENTO ha señalado el sitio que esa convención alcanzó en nuestra historia con las siguientes palabras: "Es un curso de derecho público que va a abrirse al pueblo, que no conoce, por lo general, lo que importa esa Constitución que se le ba dado"10. La prensa difundirá los trabajos de la Comisión examinadora, primero, y después los discursos que toman los taquígrafos durante las sesiones de la Asamblea. Con todo ello la Constitución adquiere una resonancia que no pudo tener cuando se la elabora silenciosamente en Santa Fe, y se la discute, premiosamente, entre el 20 de abril y el 1 de mayo de 1853 .

En el seno de la convención provincial, la Constitución de 1853 fue revisada por una comisión integrada por los convencionales Bartolomé Mitre, Dalmacio Vélez Sarsfield, José Mármol, Antonio Cruz ObliGADO, y Domingo Faustino SARMIENTO. El informe producido por dicha

10 Padilla, Alberto G.: Lecciones sobre la Constitución (primera serie), Editorial Perrot, Buenos Aires, 1961, p. 30. 
comisión revisora constituye la fundamentación de las reformas que en definitiva aprobaría la Convención Nacional ad hoc. Dicho informe fue redactado por MITRE, aun cuando sin desconocer la descollante actuación de su redactor, no puede negarse que asimismo expresa las ideas de los demás miembros de la Comisión y en particular de SARMiento y Vélez SARSFIELD, también de desempeño decisivo en las enmiendas que se proponían ${ }^{11}$.

Los ex constituyentes Gorostiaga, Seguí y Del CARril, integraron, con VÉlez SARSFIELD, MÁrMOL, ELIZALdE Y CÁCERES la Comisión designada para estudiar las reformas propuestas por Buenos Aires. En su despecho introdujo pocos cambios en los puntos sometidos y quedó aprobado en la sesión del 23 de septiembre ${ }^{12}$.

La comisión explicaba que "la publicidad de la discusión sobre las reformas propuestas por Buenos Aires y los importantes debates que se ban tenido en aquella convención y en la prensa de la República, autorizan a la comisión a excusarse de fundar las razones de su dictamen. Todos sus miembros se complacerán en dar los antecedentes y explicaciones que se pidan sobre las reformas que susciten aquella discusión"13.

Los debates de la Convención de Buenos Aires de 1860 son importantes y sustanciales, no solamente por los nuevos artículos incorporados a la Constitución, sino por el debate de fondo sobre la Constitución misma y la construcción de la unión nacional, la nueva redacción que se dio al artículo 35 es la mejor prueba de ello, pasando de la denominación "Confederación Argentina" a la de "Nación Argentina", que bien puede decirse, nace con la Constitución de $1860^{14}$.

\section{LAS REFORMAS CONSTITUCIONALES POSTERIORES}

Con el correr del tiempo, el texto histórico irá sufriendo diferentes modificaciones, y ello no solamente por las reformas constitucionales a partir del mecanismo que la propia Constitución estableciera en su artículo 30, sino también por vía de interpretación y de las leyes que reglamentan el ejercicio de la norma fundamental (conf. Art. 14 Const. Nac.)

En el siglo XIX, siglo de sanción de la Constitución se registran dos breves reformas, la de 1866 que tuvo por objeto fortalecer los recursos financieros del Gobierno Federal y la de 1898 que posibilitó elevar el número de Ministros del Poder Ejecutivo. Comenzaban a vislumbrarse

\footnotetext{
11 LINARes Quintana, Segundo V.: El espíritu de la Constitución, Linares Quintana, Badeni \& Gagliardo. Abogados, Buenos Aires, AD-HOC, 1993, p. 96.

PADIL.I.A: op. cic., p. 30.

LINARES QUINTANA: op. cit., pp. 98-99.

RAVIGNANI: "Asambleas..., op, cit.
} 
cambios que requerían de una mayor atención técnica a los asuntos de Estado, entre tales cambios se registraba la Conquista del Desierto que duplicó el territorio nacional y la capitalización de la Ciudad de Buenos Aires.

En la reforma de 1866 se trató de los artículos 4 y 67 inciso $1^{\circ}$ con el fin de dotar de mayores rentas al Gobierno Federal, comprometido por la Guerra del Paraguay, sancionándose en esa oportunidad la Ley 171 que declaró la necesidad de la reforma y fijó el temario y la Ley 172 que estableció las formalidades que debían reunir los convencionales y las formalidades para su reunión, siendo ambas leyes, dos requisitos importantes en la reglamentación del artículo 30 C.N.

Varios cambios se fueron produciendo a nivel infraconstitucional que, sin embargo, tuvieron influencia en la interpretación que la jurisprudencia de la Corte Suprema de Justicia de la Nación como "último intérprete" iría hiciendo del texto de la norma fundamental pasando desde la llamada interpretación estática (apegada al sentido literal del texto) a la interpretación dinámica (que toma en cuenta la realidad social circundante).

El punto de inflexión que marca el primer cambio en la jurisprudencia de la Corte fue el fallo "Ercolano c. Lanteri de Renshaw" (1922), con la disidencia del Ministro Antonio Bermejo.

El 28 de febrero de 1912 el Presidente RoQue SÁenZ PeÑa presentaba su reforma política que incorporaba la lista incompleta y el voto obligatorio pronunciando, entre otros los siguientes conceptos: "...Ni el gobierno ba de ser el comité, ni el comité se ha de vaciar en la administración. Yo espero de los señores gobernadores, no solo el cumplimiento de la ley, sino la influencia moral que me coloque con ellos en la misma comunión patriótica. Tengo confianza en sus declaraciones, y no creo que baya faltado a mi palabra fuerza comunicativa ni virtudes convincentes, por lo mismo que se inspira en un real desprendimiento. La representación nacional no puede ser la expresión de los gobernadores, sino la de los partidos libremente manifestada..."

Concluía finalmente con solemnes palabras "He dicho a mi país todo mi pensamiento, mis convicciones y mis esperanzas. Quiera mi país escuchar la palabra y el consejo de su primer mandatario. Quiera votar".

La sanción de la Ley 8871 no aseguró por sí el voto universal secreto y obligatorio como tampoco la Constitución aseguró por sí misma la vigencia del Estado de Derecho. Hubo reacción, turbulencias, lucha y convicciones. El 5 de mayo de 1936, el Gobernador de la Provincia de Buenos Aires, Manuel FrESCO se dirigía a su legislatura señalando que "con el sufragio universal estamos creando una raza débil y poco viril" en tanto que el 23 de noviembre de 1937 Marcelo T. de ALVEAR denunciaba "la lucha electoral más nefasta y vergonzosa" para referirse a las elecciones fraguadas del 5 de septiembre del mismo año y el 11 de febrero de 1941 
el Presidente Roberto M. ORTIZ afirmaba que "era necesario condenar toda manifestación de fraude" 15 .

Sin embargo, la Ley SÁENZ PEÑA fue un cambio fundamental para pasar del modelo "liberal-burgués" o del "estado oligárquico de derecho" hacia la república demoliberal, trasladando el poder desde las minorías ilustradas hacia las mayorías populares.

También por aquellos tiempos se sancionaron importantes leyes sociales, como la Ley 4661 de descanso dominical (1905); en 1907 se creó la Dirección General del Trabajo, que en 1912 se transforma en Departamento Nacional de Trabajo; con la sanción de la Ley 9511 (1914) se estableció la inembargabilidad de los sueldos; con la Ley 9688 (1915) se reguló lo atinente a accidentes de trabajo, la Ley 11337 (1924) reguló lo referente a trabajo de menores y de mujeres, y por Ley 11.544 (1929) se fijan límites a la jornada laboral. La encíclica Rerum Novarum así como las influencias de socialistas, anarquistas y sindicalistas influyeron en tales cambios ${ }^{16}$.

En la reforma constitucional de 1949 tuvo singular protagonismo y relevancia la figura de Arturo Enrique SAMPAY, nacido en la Provincia de Entre Ríos, pero que fue convencional por la Provincia de Buenos Aires, a la que representaba y donde había actuado previamente como Fiscal de Estado y se había destacado como profesor de Derecho Político en la Facultad de Ciencias Jurídicas y Sociales de la Universidad Nacional de La Plata. Era un estudioso de sólida formación tomista, con conocimientos del Derecho público europeo y americano, particularmente influenciado por Carl SCHMITT y el decisionismo alemán. SAMPAY presidió la comisión de estudios del anteproyecto y sería el redactor final de la reforma.

La Ley declarativa de necesidad de la reforma $n^{\circ} 13.233$ no alcanzo Ios dos tercios de votos en la Cámara de Diputados requeridos en el artículo 30 de la Constitución, circunstancia que impugnó su validez desde el mismo comienzo del proceso reformador y que concluyera en el retiro de las fuerzas opositoras de la Asamblea en una discusión que perduró hasta la caída de Perón y la derogación de la Reforma mediante una "proclama" del gobierno de la "Revolución Libertadora". El centro de la discusión de la reforma estuvo en la reelección del Presidente ${ }^{17}$.

El bloque de la oposición, por intermedio de Moisés LEBENSOHN, manifestó que el propio miembro informante de la mayoría (Arturo SAMPAY) había confesado que la reforma del artículo 77 se efectuaba

\footnotetext{
15 Dalla Via, Alberto Ricardo: Colección de Análisis Jurisprudencial. Derecho Constitucional, La Ley, 2002.

16 PÉrez Guilhou, Dardo: El Constitucionalismo, cit., p. 480.

17 FAYT, Carlos S.: La naturaleza del peronismo, Buenos Aires, 1967. Legon, Faustino y Medrano, Samuel W:: La Constitución de la Republica Argentina, Madrid, 1953.
} 
“...para Perón, con el espíritu de posibilitar la reelección de Perón”, y que los convencionales radicales se retiraban de la Convención porque el debate constituía "una farsa". Sin embargo, el retiro del bloque radical no impidió continuar sesionando a la Asamblea, porque la bancada peronista tenía quórum propio.

El contenido social se manifestó en el artículo 37 al incorporar los derechos del trabajador, la ancianidad, la familia, la educación y a la cultura, así como el artículo 68 inciso 11 que ordenaba la sanción del Código de Derecho Social; en tanto que el carácter antiindividualista de la reforma se manifestaba en el artículo 15 al manifestar que el Estado no reconocía libertad para atentar contra la libertad y por el artículo 35 que constitucionalizaba el llamado "abuso del derecho" 18 .

No obstante su amplitud, no fue una reforma total. Se agregaron dos frases al preámbulo y la parte dogmática se dividió en cuatro capítulos: I) Forma de gobierno y declaraciones políticas; II) Derechos, deberes y garantías de la libertad personal; III) Derechos del trabajador, de la familia, de la ancianidad, de la educación y cultura y IV) Función social de la propiedad, el capital y la actividad económica; en tanto que la parte orgánica no sufrió grandes modificaciones, siendo la más importante la prohibición de reelección del presidente, que se permitió sin limitaciones y sin cambiar el plazo del mandato que era de seis años.

El gobierno de la llamada "Revolución Libertadora" invalidó la reforma constitucional de 1949 y en ejercicio de "poderes revolucionarios" declaró la necesidad de la reforma en treinta (30) de sus artículos referidos al régimen electoral, sistema federal, libertades y derechos individuales, autonomías provinciales, equilibrio de poderes y fuentes de energía, entre otros temas, convocando a elecciones de convencionales constituyentes para el 28 de julio de 1957 por el sistema de representación proporcional, variante D'Hondt. Los lineamientos de la convocatoria y de los temas a reformar habían sido sugeridos por una Comisión de Estudios Constitucionales, integrada por Juan A. GONZÁLEZ CALDERÓN, Sebastián SOLER y Carlos SÁNCHEZ VIAMONTE ${ }^{19}$.

Apenas iniciadas las sesiones en Santa Fe, en la sede de la Universidad Nacional del Litoral la Asamblea tomó disposiciones que afirmaron su carácter soberano, a fin de no quedar determinada por los "poderes revolucionarios" invocados por el gobierno de facto, sino, por el contrario buscaba afirmar los poderes propios del cuerpo.

\footnotetext{
18 Sobre el tema puede verse nuestro trabajo titulado "Los Abusos en el Derecho Público" publicado como capítulo de nuestro libro Estudios sobre Constitución y Economía, Universidad Nacional Autónoma de México, 2003.

19 Ekmekdjian, Miguel Angel: Tratado de Derecho Constitucional, Tomo III, Depalma, Buenos Aires, p. 244.
} 
Finalmente, se utiliza una fórmula conciliadora para satisfacer a quienes, como el convencional Alfredo L. PALACIOS, consideraban que la convención solo podía aceptar limitaciones impuestas por ella misma, y a la mayoría que consideraba encontrarse limitada por el decreto-ley de convocatoria.

El 23 de septiembre la Convención resolvió: 1) Rechazar las impugnaciones formuladas, declarar la validez del mandato de los convencionales y la legitimidad de la Asamblea; 2) Declarar que la Constitución Nacional vigente es la de 1853, con las reformas de 1860, 1866 y 1898 , con exclusión de la de $1949 ; 3$ ) fijar los artículos sujetos a enmienda ${ }^{20}$. De ese modo, la convención trataba de seguir la línea de legitimidad del ordenamiento constitucional, sin aludir ni ratificar la proclama de septiembre de 1956.

Los cuestionamientos internos finalmente hicieron que la Asamblea quedase sin quórum y que solamente llegara a sancionarse un artículo nuevo entre el 14 y el 15 , recogiendo los derechos del trabajador de la Constitución de 1949 con el agregado del derecho de huelga que no estaba en aquella, además de incorporar la obligación de sancionar el Código del Trabajo y de la Seguridad Social en el artículo 67 inciso 11.

Las reformas a la Constitución Nacional realizadas en 1957 fueron recurridas ante la Corte Suprema de Justicia de la Nación en el leading case "Soria de Guerrero cl Bodegas y viñedos Pulenta" donde se consideró revisable la reforma constitucional en cuanto a la regularidad del procedimiento, mas no en cuanto a su contenido.

El gobierno de facto surgido del golpe militar de 1966 disolvió los partidos políticos y prohibió la realización de actos de naturaleza política por aplicación de la Ley de facto 16.894, hasta que en 1971 el Ministro del Interior, Arturo MOR ROIG anunció la rehabilitación de la actividad política y puso en marcha el proceso de reforma institucional, creándose a tal efecto una Comisión Asesora del Plan Político integrada por los Doctores Germán J. BIDART CAMPOS, Carlos María Bidegain, Natalio R. Botana, Carlos S. Fayt, Mario Justo López, Julio C. Oyhanarte, Roberto I. Peña, Pablo A. Ramella, Adolfo R. Rouzat, Alberto A. SPOTA y Jorge R. VANOSSI.

Esa Comisión remitió al presidente de facto Alejandro A. LANUSSE un informe sobre las reformas constitucionales propuestas con una serie de dictámenes independientes, coincidentes algunos y otros en disiden$\mathrm{cia}^{21}$. De conformidad con los mismos, la Junta de Comandantes en Jefe

\footnotetext{
20 Convención Nacional Constituyente de 1957, Diario de Sesiones, Buenos Aires, 1958, Tomo I, pp. 750 y ss.

21 Informe de la Comisión Asesora para la reforma institucional, Imprenta del Congreso de la Nación, Buenos Aires, 1972.
} 
sancionó la Ley de facto 19.608 denominada "ley declarativa fundamental" que declaró la necesidad de una serie de reformas a la Constitución.

Las reformas se efectuaron por un "Estatuto Fundamental" del 24 de agosto de 1972 y se refirieron exclusivamente a la parte orgánica de la Constitución y, en lo sustancial, consistieron en la unificación de los mandatos en cuatro años, en la supresión de los colegios electorales aplicándose el sistema de doble vuelta para presidente, vice y senadores, suprimiendo el juicio político a los jueces inferiores de la Corte Suprema de Justicia, que sería reemplazado por un jury, etc.

Ese mismo Estatuto dispuso que tendría vigencia hasta mayo de 1977 y, salvo que una convención constituyente no decidiera su incorporación definitiva al texto constitucional o su derogación antes del 25 de agosto de 1976, su vigencia quedaba prorrogada hasta el 24 de mayo de 1981. Finalmente el golpe militar de marzo de 1976 que dio lugar al llamado "Proceso de Reorganización Nacional" interrumpió el camino constitucional que se había retomado en marzo de 1973 y las posibles expectativas que se habían creado. Se ha señalado que la aplicación del mencionado "Estatuto" era -cuanto menos- incoherente y de discutida legalidad ${ }^{22}$.

\section{LA REFORMA CONSTITUCIONAL DE 1994}

La reforma constitucional de 1994 originó un intenso debate en lo referido a la etapa "preconstituyente", si se utiliza la terminología introducida por SÁNCHEZ VIAMONTE para designar al procedimiento de declaración de "necesidad de la reforma" por parte del Congreso de la Nación, conforme lo señalado por el artículo 30 de la Constitución Nacional; cuestiones que fueron subsanadas jurídicamente y en parte superadas políticamente por los hechos posteriores, de una etapa constituyente reformadora que cumplió a ritmo regular y puntual el objetivo de reformar la Constitución histórica de 1853/60.

La Convención sesionó en la ciudad de Santa Fe, realizándose los actos de inauguración y de clausura, como así también algunas reuniones de comisiones en la ciudad de Paraná; se cumplió el plazo previsto y la Constitución reformada fue sancionada antes de los noventa días, y fueron tratados todos los temas previstos por la Ley 24.309, tanto los del llamado "núcleo de coincidencias básicas" (art. 2) como los llamados temas "habilitados" (art. 3). El 24 de agosto de 1994 tuvo lugar en Concepción del Uruguay la jura de la Constitución de 1853, con las reformas de 
$1860,1866,1898,1957$ y 1994 . Se trató, por lo tanto, de un caso de ejercicio del poder constituyente reformador o derivado ${ }^{23}$.

De todos los proyectos y antecedentes de reforma, los que más se han reflejado en la labor constituyente fueron los de la Reforma Transitoria de 1972 y los "Dictámenes" del denominado "Consejo para la Consolidación de la Democracia"24.

Del primero se reflejan distintas formulaciones de técnica legislativa en cuanto al difundido objetivo de "modernizar las instituciones", prolongando las sesiones del Congreso, promoviendo el trabajo en comisiones; como así también la propuesta de fijar el mandato del Presidente y Vicepresidente de la Nación en cuatro años, con una sola reelección; la elección directa del Presidente y los Senadores, la elección de un tercer Senador por la minoría, etc.

Por su parte, se desprende de los "Dictámenes" del Consejo para la Consolidación de la democracia, la idea de morigerar el exceso de poder presidencial, con cierta tendencia a "parlamentarizar" el sistema, a través de la incorporación de un "Ministro Coordinador" que, además de ejercer algunas funciones específicas en materia administrativa, presupuestaria, etc. Acerque, articule y haga más funcional la relación entre los poderes.

Se observa también, en ese sentido y de acuerdo con el mismo antecedente, el interés de darle un rol especial al Senado en la iniciativa de algunos proyectos que tienen que ver con la materia federal (coparticipación, art. 75 inc. $2^{\circ}$; desarrollo territorial armónico, art. 75 inc. 19), así como otros temas que también fueron considerados en el proyecto mencionado como el Consejo de la Magistratura, la Defensa del Medio Ambiente, etc.

En los contenidos de ambos proyectos, y en su posterior cristalización en el texto de la Constitución reformada, aparecen los principales contenidos teleológicos que la reforma ha presentado en distintas formulaciones, tales como: la necesidad de modernizar y agilizar el funcionamiento de las instituciones; fortalecer los mecanismos de control del poder, delimitando las funciones; atenuar los excesos del presidencialismo hegemónico; instrumentar la inserción internacional de la Argentina; fortalecer el federalismo; etcétera.

23 Dalla Via, Alberto Ricardo: Constitución de la Nación Argentina. Texto según la reforma constitucional de 1994, Librería Editora Platense, 2ª Edición, 1996. Capítulo preliminar "Balance de la Reforma constitucional", p. 5.

24 El Consejo para la Consolidación de la Democracia fue creado por el Decreto 2446/85, bajo la coordinación del Dr. Carlos S. NINO. Publicó dos dictámenes sobre la reforma Constitucional. El "tercer dictamen", referido a los temas económicos, quedó sin publicar. 
La reforma constitucional de 1994 ha sido muy rica en la incorporación de principios ideológicos. El catálogo de derechos declarados, y de garantías, se ha ampliado apuntando al valor de la "solidaridad". La "participación" es otro de los valores afirmados, haciendo a la Constitución más democrática. Ha afirmado también el constituyente un concepto más social y material de la igualdad, que viene a completar el concepto de igualdad formal del artículo 16 con un nuevo criterio interpretativo, cual es el de la "igualdad de oportunidades" que aparece repetido en distintas partes del texto y en la consagración de "acciones positivas" que tendrá a su cargo el Estado para combatir toda forma de discriminación (art. 75, inc. 23).

El "tono" general de la reforma, en lo ideológico, se ha corrido más hacia la afirmación de principios del Estado social que del constitucionalismo liberal. El ingreso de una cantidad de principios que no estaban expresamente consagrados en el texto se da por la cantidad de tratados internacionales que pasan a tener "jerarquía constitucional" (art. 75, inc. 22) y que, por la época en que dichos tratados fueron suscriptos, se enmarcan claramente en la etapa del constitucionalismo social de posguerra y anterior a la crisis mundial del petróleo que trajo también aparejada la crisis del Estado social de Derecho.

Resulta también paradójico que estos principios hayan sido afirmados por el constituyente en pleno tiempo de "ajuste" hacia un pretendido modelo de Estado "neoliberal". No hay, en cambio, en la reforma reciente ningún artículo que proclame la libertad económica ni la economía de mercado.

No aparece un "programa constitucional" como exhibió la Constitución histórica, no aparece el telos ni el "modelo" del texto constitucional, por el contrario, y como dijimos al principio, hay muchos aspectos fundamentales que quedaron sin definirse y con el riesgo, potencial o real, de que eso pueda ocurrir.

Los dos principios incorporados que tienen más importancia en materia económica son el derecho al medio ambiente (art. 41) y la integración económica latinoamericana (art. 75, inc. 24), por su inevitable repercusión, tanto en los derechos económicos como en los principios orientadores de la política económica.

De estos principios, y de otros que consagran los derechos de usuarios y consumidores (art. 42), así como la posibilidad de ejercitar la acción de amparo contra los titulares de servicios públicos privatizados (art. 43), se desprende -aunque no esté claramente dicho- que se propugna un modelo de competencia, dentro del cual cabe al Estado un rol regulador para que el mercado funcione.

Pero el "núcleo" ideológico de la reforma está en el inciso 19 del artículo 75 , ubicado a continuación de la "cláusula del progreso" (ex art. 67 , inc. 16). La nueva norma se ha dado en llamar "cláusula del nuevo 
progreso" 25 o "cláusula del progreso económico y social" 26 , donde se establecen como valores fundamentales a "proveer" por la legislación: "...al desarrollo humano, al progreso económico con justicia social, a la productividad de la economía nacional, a la generación de empleo, a la formación profesional de los trabajadores, a la defensa del valor de la moneda, a la investigación y al desarrollo científico y tecnológico, su difusión y aprovechamiento..." ( $\mathrm{l}^{\mathrm{er}}$ párr.).

El término "desarrollo humano" aparece repetido en otros artículos y debe vincularse con la interpretación dada por la Organización de las Naciones Unidas (ONU) en tanto se toma al denominado índice de desarrollo humano (IDH) para medir el grado de avance de los países, con parámetros que no solo contemplen el crecimiento económico, sino también los niveles de educación, de ocupación, de vivienda, de cultura, etcétera. En ese mismo sentido, el término "progreso económico" se diferencia del mero crecimiento económico mientras aquel marca simplemente diferencias en el producto bruto, en tanto el "progreso" denota una idea de avance en una dirección ética predeterminada ${ }^{27}$.

El segundo párrafo plantea el objetivo del equilibrio territorial en los siguientes términos: "Proveer al crecimiento armónico de la Nación y al poblamiento de su territorio; promover politicas diferenciadas que tiendan a equilibrar el desigual desarrollo relativo de provincias y regiones. Para estas iniciativas el Senado será Cámara de origen".

En materia de educación se establece: "...Sancionar leyes de organización y de base de la educación que consoliden la unidad nacional respetando las particularidades provinciales y locales; que aseguren la responsabilidad indelegable del Estado, la participación de la familia y la sociedad, la promoción de los valores democráticos y la igualdad de oportunidades y posibilidades sin discriminación alguna; y que garanticen los principios de gratuidad y equidad de la educación pública estatal y la autonomía y autarquía de las universidades nacionales" ( $3^{\text {er }}$ párr.).

Y finalmente: "Dictar leyes que protejan la identidad y pluralidad cultural, la libre creación y circulación de las obras del autor; el patrimonio artístico y los espacios culturales y audiovisuales" (últ. párr.).

Es de destacar también que la reforma se ha basado en antecedentes diferentes a los que tuvo por vista la "Constitución histórica". Resulta obvio señalar que el constituyente no tuvo por base documentos similares a las Bases ni al Proyecto de Constitución de Juan Bautista ALBERDI; la

Dalla VIA, Alberto Ricardo: Constitución de la Nación Argentina, op. cit.

Ver Constitución de la Nación Argentina, con prólogo de Néstor SAGứs, Depalma, Buenos Aires, 1994.

Sobre el rema véase DALla VIA, Alberto Ricardo, Transformación Económica y Seguridad Jurídica, Platense, La Plata, $2^{a}$ Edición, 1996. 
reforma de 1994 tuvo principalmente en cuenta, entre otros documentos, a los "Dictámenes" del denominado Consejo para Consolidación de la Democracia y a la "reforma provisoria de 1972" impulsada por un gobierno de facto ${ }^{28}$, que pusieron el acento en la atenuación del "hiperpresidencialismo", el primero, y en la agilización de las funciones del Congreso, el segundo; entre otros importantes aspectos.

Pero el dato más importante a destacar en este sentido es que la Constitución histórica recibió en su interpretación la influencia del constitucionalismo estadounidense por vía de la jurisprudencia de la Supreme Court y por los escritos doctrinarios, especialmente los recopilados en $\mathrm{El}$ Federalista por MADISON, HAMILTON y JAY. No pocas veces se ha afirmado que la Constitución argentina había sido "vaciada" sobre los moldes de la norteamericana, tema que fue objeto de una aguda polémica entre AlBERDi y SARMIENTO. La influencia de la jurisprudencia norteamericana sobre nuestra Corte Suprema ha sido muy importante y en muchos temas han seguido líneas paralelas, como ha ocurrido, por ejemplo, con la doctrina del "poder de policía".

La reforma de 1994 estuvo, en cambio, muy influida por el constitucionalismo europeo en el diseño de las nuevas instituciones propuestas (ej.: defensor del pueblo, nuevas garantías, etc.) y entre estas, ha tenido una marcada influencia la Constitución española de 1978 que ha servido de base y modelo para la redacción de distintos artículos. En ese sentido, mientras la bicentenaria Constitución norteamericana adscribe al liberalismo individualista, la Constitución española, una de las más recientes de Europa, proclama un Estado social y democrático de Derecho (art. 1.1).

\section{EL PODER CONSTITUYENTE DERIVADO O REFORMADOR}

No solo se reformó una cantidad importante de artículos y se agregaron nuevas disposiciones, sino que también se ha modificado el "lenguaje", el estilo claro y abierto que caracterizaba a la norma fundamental que habían redactado Benjamín Gorostiaga y Juan María GuTIÉrREZ, principalmente. Estas razones han hecho frecuente el uso de la expresión "nueva Constitución" y nos lleva a planteamos si se trata de una Constitución nueva o reformada. Para nosotros está claro que debe hablarse de la "Constitución reformada", no solamente porque se trató de un caso de ejercicio de poder constituyente derivado (art. 30, Const, Nac.), sino porque expresamente fue jurada la Constitución Nacional de 1853, con las reformas de $1860 ; 1866 ; 1898 ; 1957$ y 1994 . Legitimándose la reforma de 1957 y excluyendo la de 1949.

Ver Dali.a Via: Constitución..., op. cit. "Introducción (Balance de la reforma)". 
Para nosotros no se trata solamente de una cuestión terminológica. En efecto, según se trate de una u otra cosa, cambiará la interpretación de la misma. Si se tratara de una constitución "nueva", debiera centrarse la interpretación en los nuevos principios incorporados, en tanto que tratándose, como es el caso, de la Constitución histórica reformada, los nuevos principios deben interpretarse a la luz de los primeros y buscando el sentido que los complemente y adapte sin perder la dirección original. Esta otra razón nos reafirma aún más en el criterio de interpretar que estamos ante una norma reformada y no ante una norma nueva.

Dicho todo esto, y tomando como premisa el carácter "liberal" de la Constitución de 1853 , con algún ingrediente "social" proveniente de la reforma constitucional de 1957 y una influencia "católica tradicional" si aceptamos la posición de SAGÜÉS de acuerdo con lo ya analizado; corresponde ahora determinar cuál es la ideología predominante en nuestra Constitución Nacional después del paso del constituyente de 1994, con su impronta aún más social, afirmadora del concepto de "desarrollo humano" de la "justicia social" y de la "igualdad real de oportunidades", al tiempo que consagrar un derecho constitucional al "ambiente sano y equilibrado para las generaciones actuales y futuras" (art. 41) determina una componente ecológica que no solo es obligación del Estado sino también, y fundamentalmente, una postura ética. El pensamiento católico tradicional, por su parte, parece haber sufrido un retraimiento al eliminarse el requisito confesional para ser Presidente de la Nación y al haberse desarrollado una "moral pública" no necesariamente identificada con el cristianismo.

Cabe preguntarse, ¿cuál es entonces actualmente el ideario constitucional argentino? ¿Cuáles son los principios dominantes entre tanta confluencia de ideas? Creemos que si bien la respuesta debe buscarse en los principios expresados en el texto constitucional, ellos no deben independizarse de una realidad circundante, de carácter sociológico, según gusta de decir BIDART CAMPOS, y que abarca la experiencia histórica, las preferencias sociales y el sentimiento colectivo. Por todas las razones expuestas, bien puede concluirse, a nuestro juicio, que el "constitucionalismo social" resalta en la Constitución argentina.

Pero es de advertir que el término no debe interpretarse bajo el estigma de izquierdas o derechas, superadas por la historia y las mismas realidades, como bien lo enseñara Norberto $\mathrm{BOBBIO}^{29}$. Por el contrario, en la Constitución argentina, el constitucionalismo social solo se entiende dentro, y no fuera, de la economía de mercado, como una continuidad "racional" del Estado liberal, reiterando lo expresado por 
VANOSSI ${ }^{30}$. De ese modo, el constitucionalismo social argentino es una síntesis del pensamiento constitucional que no contradice ni desecha los principios liberales, sino que los afirma en el sentido del nuevo Estado: el modelo de competencia.

Pocas dudas pueden caber sobre la afirmación en cuanto que el constitucionalismo se encuentra ligado al sistema capitalista. No solo por sus orígenes, sino también porque el muro de Berlín ha caído, y con él, también, las utopías que pretendieron alejar al desarrollo económico de su intrínseca relación con el Estado de Derecho. Ya Maurice DUVerger había señalado, años atrás, que era la economía de mercado la que se correspondía con el sistema democrático, al priorizar, ambos, la libertad ${ }^{31}$. La experiencia también demuestra que los niveles más altos de desarrollo se dan en aquellos países que guardan una adecuada correlación entre libertad económica y libertad política, como se desprende de los informes del Programa de Naciones Unidas para el Desarrollo (PNUD), donde se afirma: “...Es claro, al menos, que en la actualidad, los países que registran un mejor desempeño económico (medido de acuerdo con el PBI o IDH) son también aquellos con una mayor dosis de libertad. Inclusive en países en donde el desarrollo económico y la libertad no han ido a la par durante algunos períodos (como en Europa oriental y el norte de Asia), ahora uno y otra se están acercando..."32.

Hoy la opción se da dentro del sistema capitalista, para determinar qué tipo de capitalismo queremos, uno que tenga al hombre como protagonista u otro que someta todo a la decisión del mercado. Esta opción ha sido planteada con gran lucidez por Michel ALBERT en su difundida obra Capitalismo contra Capitalismo, donde se plantea este debate $^{33}$. De ese modo el "neoliberalismo" es entendido como una revalorización de la economía de mercado que recoge los aportes del Estado social de Derecho en orden a corregir las deformaciones y desigualdades que el mercado produce ya realizar una sociedad más justa y equitativa. En la Teoría de la Justicia, de John RAWLS, se desarrolla y fundamenta esta importante cuestión. Es en este marco ideológico donde se aboga por una relación adecuada entre "transformación económica y seguridad jurídica" que coordine el principio económico de la eficacia con un Estado eficiente para asegurar los valores sociales, por-

\footnotetext{
30 VANOSSI, El Estado..., cit.

31 Duverguer, Maurice: Instituciones Políticas y Derecho Constitucional, rrad. de Pablo Lucas Verdú, Ariel, Barcelona, 1988.

32 Desarrollo Humano, Informe 1992, Cap. 2, "Libertad política y crecimiento económico", p. 70 .

33 Albert, Michel: Capitalismo contra Capitalismo, Paidós, Colección "Estado y Sociedad", Buenos Aires, 1997.
} 
que como bien señalara Octavio PAZ, "el mercado sirve para fijar precios, pero no valores sociales" 34 .

Es por eso que el ideario constitucional argentino no se ha modificado sino que se ha completado a la luz de los aportes doctrinarios y de la necesidad de los tiempos, sin perder el norte libertario abierto en la gesta de mayo y grabado en el texto constitucional de 1853 a favor de la libertad y la iniciativa individual; hoy la preocupación por el desarrollo humano pone su impronta definitoria en el texto para elegir por un capitalismo con rostro humano frente al economicismo del ajuste por el ajuste mismo. En esa línea también aparece el nuevo pensamiento de la doctrina de la Iglesia Católica, que a partir de la encíclica Centesimus Annus, del Papa JUAN PABLO II, reivindica el papel de la iniciativa individual en el desarrollo económico.

\section{BIBLIOGRAFÍA REFERIDA}

- AlBerdi, Juan Bautista: “Juan María Gutiérrez. Biografías y autobiografías", en Obras Selectas de Alberdi, Ed. La Facultad, 1920, T. IV.

- Albert, Michel: Capitalismo contra Capitalismo, Paidós, Colección "Estado y Sociedad", Buenos Aires, 1997.

- BobBio, Norberto: El Futuro de la Democracia, Colección "Política y Derecho", Fondo de Cultura Económica, México.

- Convención Nacional Constituyente de 1957, Diario de Sesiones, Buenos Aires, 1958, Tomo I.

- Dalla Via, Alberto Ricardo: Colección de Análisis Jurisprudencial. Derecho Constitucional, La Ley, 2002.

- Dalla Via, Alberto Ricardo: Constitución de la Nación Argentina. Texto según la reforma constitucional de 1994, Librería Editora Platense, $2^{\mathrm{a}}$ Edición, 1996. Capítulo preliminar "Balance de la Reforma constitucional".

- Dalla VIA, Alberto Ricardo, Transformación Económica y Seguridad Jurídica, Platense, La Plata, $2^{\text {a }}$ Edición, 1996.

- Díaz ARANa (h) Juan José: Influencia de Alberdi en la Constitución Nacional. Juicio ante una controversia, Librería Jurídica Valerio Abeledo - Editor, Buenos Aires, 1947.

- Dalla Via, Alberto Ricardo: "Los Abusos en el Derecho Público", capítulo de libro Estudios sobre Constitución y Economía, Universidad Nacional Autónoma de México, 2003.

- Desarrollo Humano, Informe 1992, Cap. 2, "Libertad política y crecimiento económico". 
- Duverguer, Maurice: Instituciones Políticas y Derecho Constitucional, trad. de Pablo Lucas Verdú, Ariel, Barcelona, 1988.

- Ekmekdjian, Miguel Angel: Tratado de Derecho Constitucional, Tomo III, Depalma, Buenos Aires, p. 244.

- FaYt, Carlos S.: La naturaleza del peronismo, Buenos Aires, 1967.

- GAletTI, Alfredo: Historia Constitucional Argentina, Librería Editora Platense, Tomo 2.

- Legon, Faustino y Medrano, Samuel W.: La Constitución de la Republica Argentina, Madrid, 1953.

- Linares Quintana, Segundo V.: El espíritu de la Constitución, Linares Quintana, Badeni \& Gagliardo. Abogados, Buenos Aires, ADHOC, 1993.

- LuNA, Félix: "Conflictos y armonías en la bistoria argentina", Planeta.

- Padilla, Alberto G.: Lecciones sobre la Constitución (primera serie), Editorial Perrot, Buenos Aires, 1961.

- QuesadA, Ernesto: La figura histórica de Alberdi, Imprenta Scherone, $2^{a}$ Edición, 1919.

- QuesadA, Ernesto: carta enviada al Dr. Juan A. González Calderón publicada en la obra de este, Derecho Constitucional Argentino, Ed. J. Lajounae y Cia., 1923. T. II.

- Ravignani, Emilio: Asambleas Constituyentes Argentinas, publicada por el Instituto de Investigaciones Históricas de la facultad de Filosofía y Letras de la Universidad de Buenos Aires, Tomo VI, p. 778.

- Informe de la Comisión Asesora para la reforma institucional, Imprenta del Congreso de la Nación, Buenos Aires, 1972.

- VANOSSI, Jorge Reinaldo A.: Cuál es el actual status institucional de la República Argentina, La Ley, Buenos Aires, 23 de abril de 1975. 